\title{
CLINICAL STUDY AND EVALUATION OF COMMUNITY ACQUIRED PNEUMONIA, SEVERITY ASSESSMENT BY CURB 65 AND PNEUMONIA SEVERITY INDEX (PSI)
}

\author{
C. A Umesh Varma1, G. Sundar Raj², P. Yugandhar ${ }^{3}$, S. Satya Sri ${ }^{4}$ \\ ${ }^{1}$ Ex-Junior Resident, Department of Pulmonary Medicine, Asram Medical College, Eluru, Andhra Pradesh. \\ ${ }^{2}$ Associate Professor, Department of Pulmonary Medicine, Asram Medical College, Eluru, Andhra Pradesh. \\ ${ }^{3}$ Professor, Department of Pulmonary Medicine, Asram Medical College, Eluru, Andhra Pradesh. \\ ${ }^{4}$ Professor \& HOD, Department of Pulmonary Medicine, Asram Medical College, Eluru, Andhra Pradesh.
}

\begin{abstract}
The study was carried out in ASRAM hospital, eluru, over a period of 2 years from August 2012 to august 2014 . The study was designated as prospective, observational, cohort study, which includes 100 cases of CAP selected on the basis of full filling the inclusion and exclusion criteria. Community acquired pneumonia continues to be a common clinical problem especially in elderly people. Males were more commonly affected than females but it was statistically not significant. Community acquired pneumonia is one of the common diagnosis in patients admitted in ICU and Emergency settings.DM and COPD are the most common co morbidities followed by rhinitis and smoking is the commonest risk factor for CAP. Cough, fever and expectoration are common and classical symptoms of pneumonia and significant number of patients with CAP can present with GI symptoms. Tachycardia, Tachypnea, Altered Mental Status, Hypotension, Cyanosis, acidosis, low albumin levels are few signs which indicate that illness is severe and critical and crepitations over chest on auscultation was the most common finding. Mean duration of stay was 8.99 days indicating it can cause significant loss in the form of economic loss if earning member of family is affected. Duration of stay was also prolonged in patients who are aged 65 and above, in patients who are undernourished, in patients with COPD and in patients who were treated with antibiotics prior to hospitalization but statistically these findings were not significant. In radiography Lower zones are most common site of involvement followed by mid and upper zones, Right lower zone was most common among all. Neutrophilic leucocytosis was the most common finding in haemogram. Gram positive organisms were more commonly seen than gram negative organisms on sputum gram's staining. Complications noticed were a)Need for ventilatory support both invasive or Non Invasive, b)Need for inotropic support for septic shock, c)Renal failure and need of temporary renal replacement, d)Sepsis and MODS, e) Prolonged ventilator support and need for Tracheostomy. CAP is a disease with significant mortality-18\% in our study. It seems the resistance to penicillins and simple antibiotics may be rising. And need of extended spectrum pencillins and a higher antibiotic is also rising but there is a need for larger studies to confirm the same. CURB-65 class $>3$, PSI class $>4$ class were having sensitivity of $41.67 \%$ and $91.67 \%$ in predicting ICU admission with a specificity of $89.5 \%$ and $59.21 \%$ respectively. Their sensitivity in predicting death was $44.40 \%$ and $88.9 \%$ with a specificity of $87.80 \%$ and $54.88 \%$ respectively. In both PSI scoring systems, mortality rate, need for intensive care unit (ICU) admission increased progressively with increasing scores but CURB-65 score did not show this correlation. PSI class of 4 and above is most sensitive and CURB 65 class of 3 and above is most specific in predicting both death and ICU admission. Both PSI and CURB 65 are complementary to each other in predicting mortality and ICU admission. But if patient fits in PSI class of 5 or CURB 65 class of 4 and above any one of criteria can be used as both were highly specific. In brief; at tertiary care centers where all laboratory reports are available within a few hours PSI scoring system can be used as a prognostic index whereas in primary or secondary care centers where it is difficult to get investigations done in a short span of time CURB 65 scoring system can be used as most of its parameters are based on clinical assessment.
\end{abstract}

KEYWORDS: CAP - Community Acquired Pnemonia - PSI-Pneumonia Severity Index-CURB 65.

HOW TO CITE THIS ARTICLE: C.A Umesh Varma, G. Sundar Raj, P. Yugandhar, S. Satya Sri. "Clinical Study and Evaluation of Community Acquired Pneumonia, Severity Assessing by Curb 65 And Pneumonia Severity Index (Psi)". Journal of Evolution of Medical and Dental Sciences 2015; Vol. 4, Issue 88, November 02; Page: 15349-15355, DOI: 10.14260/jemds/2015/2184.

INTRODUCTION: According to recent data pneumonia is the third leading cause of death in the world and fourth leading cause of death in India, inspite of advancement of medical science and vast number of good antibiotics, which represents a significant burden to country.

It causes $7 \%$ of all the deaths yearly in world. Incidence of pneumonia is five times more frequently

Financial or Other, Competing Interest: None.

Submission 08-10-2015, Peer Review 09-10-2015,

Acceptance 20-10-2015, Published 02-11-2015.

Corresponding Author:

Dr. C. A Umesh Varma,

D. No. 45/24 b 2a, Ashok Nagar, Kurnool,

Andhra Pradesh.

E-mail: umeshvarmambbs@gmail.com

DOI: $10.14260 /$ jemds $/ 2015 / 2184$. occurring in developing world compared with the developed countries. Despite being the cause of significant morbidity and mortality, pneumonia is often misdiagnosed, mistreated, and underestimated.

Pneumonia is an infection of the pulmonary parenchyma and pneumonia that develops outside the hospital is considered community acquired Pneumonia. New radiographic infiltrate in the presence of evidence of infection (Fever, purulent sputum, leucocytosis) with onset at least 72 hours after hospital admission is called Nosocomial pneumonia.

Little information is available from India regarding prognostic factors in patients with CAP and moreover only few studies are conducted till date in India, even with Extensive laboratory testing and invasive procedures etiology being achieved in $<50 \%$ from sputum samples. 
Prognostic scoring systems like CURB-65,PSI INDEX,SOAR INDEX,SMART COP INDEX,SMART COP,ATS IDSA CRITERIA for CAP were developed to assess severity of illness ^ (id classify patients on basis of mortality risk, recognition of Seriously ill patients regarding management and proper triage for the need of hospital admission and ICU admission. These scoring systems also provide meaningful information for physicians to discuss prognosis with patients family.

AIMS AND OBJECTIVES: AIM: The aim of our study is to assess the validity of CURB 65 and Pneumonia Severity Index in patients admitted with community acquired pneumonia in our hospital

\section{OBJECTIVES OF THE STUDY:}

1. Analysis of clinical spectrum, causes, prognostic factors of CAP.

2. To assess severity based on Pneumonia Severity Index.

3. To relate CURB 65 score to prognosis.

4. To compare Pneumonia Severity Index and CURB 65 in assessing severity of CAP.

\section{MATERIALS AND METHODS:}

Source of Data: The study was carried out in ASRAM hospital, eluru, over a period of 2 years from August 2012 to august 2014. The study was designated as prospective, observational, cohort study, which includes 100 cases of CAP selected on the basis of full filling the inclusion and exclusion criteria.

\section{Inclusion Criteria:}

- Subjects 18 yrs. or more.

- CAP diagnosed based on

- Presence of infiltrates on CXR consistent with consolidation and associated with respiratory symptoms

- And (2 out of 3)

i. Fever

ii. Cough

iii. Neutrophilia or elevated total leucocyte counts.

\section{Exclusion Criteria:}

- Refused consent.

- Opportunistic pneumonia.

- Active pulmonary TB.

- Immunosuppressed (HIV positive, solid organ transplant, post splenectomy).

- Cryptogenic organizing pneumonia (COP).

- Ventilator associated pneumonia.

- Hospital acquired pneumonia (hospitalized within previous 14 days or developed $>72 \mathrm{hrs}$. after admission).

- Lung malignancies.

\section{Method of Collection of Data:}

- A detailed proforma was filled up for each patient, which included age, sex, IP number, detailed history, past and personal history. A clinical examination was done. Laboratory parameters including complete blood counts, blood glucose, renal function tests, liver function tests, blood gas analysis, HIV ELISA, blood culture and ECG and routine urine examination were done:
- Patient is investigated for chest $\mathrm{x}$-ray, sputum for gram stain, culture and sensitivity pattern, AFB,

- BAL, CT thorax, pleural fluid analysis were done only for required cases.

- All patients will be clinically and radio graphically reassessed after $48 \mathrm{hrs}$ to look for development of complications or to assess amount of improvement.

All the variables were collected and CURB 65 score and PSI score was calculated for each patient and CLASS was assigned to each patient.

\section{STATISTICAL METHOD APPLIED:}

Frequencies: The frequencies procedure provides statistics and graphical display that are useful for describing many types of variables. The frequencies procedure is a good place to start looking at .our data.

Desriptives statistics: The Descriptives produces displays univariate summary statistics for several variable in a signal and calculates standardized values. Variables can be ordered by the size of means. In the present study descriptive statistics were calculated for individual statements as well as the total scores for each component.

Crosstabs (contingency coefficient test): The Crosstabs procedure forms two-way and multiway tables and produces a variety of and measures of association for two-way tables. The structure of the table and whether categories are order determine what test or measure to use.

Independent- sample $\mathbf{T}$ Test: The Independent $\mathrm{T}$ Test produces compares means for two groups, so that any difference in response is due to the treatment (or lack of treatment) and not to other factor. This is not the case if you compare average income for males and females. A person is not randomly assigned to be a male or. In such situations, you should ensure that difference in other factor are not masking or enhancing a significant difference in means. Difference in average income may be influenced by factor such as education and not by sex alone.

ONE-WAY ANOVA: The one-way ANOVA produces a one-way analysis of variance for a quantitative dependent variable. Analysis of variance is used test hypothesis that several means are equal. The technique is an extension of the-sample test. In present study one-way ANOVA was applied to find out the significance of difference between mean scores Scheffe's post hoc tests.

In addition determining that difference exists among the means, you may want to know which means differ. There are two types of tests for comparing means experiment, and post hoc test are running the experiment, and post hoc test are run after the experiment has been conducted. You can also test for trends across categories.

All the statistical calculations were done through SPSS16.0 (2007) for windows.

RESULTS: Total 106 patients were enrolled in the study, 6excluded, as 4 were sputum for AFB positive TB, and one patient had tubercular pleural effusion, another patient was on long term steroids for Bronchial asthma. Therefore study included 100 cases of CAP selected on the basis of fulfilling inclusion and exclusion criteria. 
DISCUSSION: The study was carried out in ASRAM College over a period of 2 years i.e from. August 2012 to august 2014.The study was designated as a prospective observation cohort study which includes 100 cases of CAP selected on the basis of fulfilling the inclusion and exclusion criteria.

In the initial management of patients with suspected CAP the clinician is faced with diagnostic and prognostic challenges, each challenge corresponding to a specific management decision. This emphasizes the importance of prompt and accurate diagnosis. The severity of illness which corresponds to decisions regarding place of admission in hospital, as it is most important decision in the overall management of CAP. It has consequences both for the level of treatment received by the patient, outcome, and the overall cost of treatment. ${ }^{1}$

Total 106 pts were enrolled in study, 6 excluded, as 4 pts were sputum for AFB positive TB and one pt had tubercular pleural effusion, another patient was on long term steroids for Bronchial asthma. Therefore study included 100 cases of CAP selected on the basis of fulfilling the inclusion and exclusion criteria.

Age of Patients: Patients in the CAP study had wide range of distribution varying from 18 to 90 in males and 18 to 82 in females; the mean age was $56.45 \pm 16.28$.

Again age is a very important risk factor for development of pneumonia, in this study $26 \%$ of patients with CAP were aged $65 \&$ above. $71 \%$ of patients were aged $50 \&$ above and test statistics were significant with $\mathrm{p}$ value of $<0.0001$ indicating that risk of CAP increases with increasing age.

These results were almost similar to a study done in Shimla, India by S.Bansal et $\mathrm{al}^{2}$ which was $52.77 \pm 18.1$ years and a Turkish study by Aydogdu et al $^{3}$ which was $68 \pm 16$ years and also in one more study done at AIIMS, India by DEY et al, ${ }^{4}$ which was 50.6 years.

Sex of the Patients: In this study $65 \%$ of patients were males and $35 \%$ were females even though male patients was affected in more number this result was statistically insignificant ( $p$ value 0.667 ) to conclude that male sex was a risk factor.

This ratio was almost similar to other studies 50 males: 20 females in study by S.Bansal et al. ${ }^{2} 63$ males: 38 females by Aydogdu et al. ${ }^{3}$ and 46 males: 26 females in study by DEY et al. ${ }^{4}$

Out of 26 who were aged 65 and above 16 were males and 10 were females making almost 1.6:1 ratio in geriatric group.

Site of Admission: In our study $24 \%$ of included patients were from ICU setting, 27\% was from emergency setting and $49 \%$ were from medicine and pulmonology wards.

The distribution of site of admission differs little in other studies Aydogduet al it was 59.4\% in emergency, $14.85 \%$ in ICU and $25.7 \%$ from wards.

In our study from table and chart 4 we can appreciate as the severity of breathlessness increases the need of ICU admission. (Grading used is ATS Grading). ${ }^{6}$

Risk Factors and Co-Morbidities: The most common risk factor was smoking. Next most common risk factor was Rhinitis either allergic/infective DM was most common co- morbid condition in our study with 40 patients and 2nd most common was COPD with 32 patients. Of the listed comorbidities $28 \%$ of patients had $>1$ co-morbidity.

In study by S.Bansalet al2 COPD was most common comorbid condition and DM was very minimal amounting to only $4.2 \% .26 \%$ of patients were already initiated on antibiotics prior to hospitalization.

In study by DEY et al. ${ }^{4}$ only $8.5 \%$ received antibiotics prior to hospitalization.

Pulmonary disorders followed by Congestive heart failure was common co-morbidities in study by Aydogduet al3and also in study by DEY et al. ${ }^{4}$

Symptoms of Cap: Most common symptoms in our study cohort was cough followed by fever and expectoration $45 \%$ of patients had mucopurulent type of sputum, $37 \%$ of patients had mucoid type of sputum and $18 \%$ did not give any complaints of expectoration.59\% of patients complained of some degree of breathlessness and 24pts had very severe breathlessness, $26 \%$ of patients gave history of GI symptoms in the form of vomiting, loose stools and decreased appetite. $10 \%$ patients complained of hemoptysis during period of illness.The pattern was almost similar in patients under study by S.Bansalet al. ${ }^{2}$ but GI symptoms was noticed more in patients included in our study.

Duration of Symptoms: Mean duration of cough is $5.57 \pm 4.60$ days (range 0-20 days), and Mean duration of fever is 5.05 days \pm 4.12 days (range 0 - 21 days).

Our findings were similar to a study by S. Bansalet al. ${ }^{2}$ It was 6 days (range $<1$ to 30 days). And it was about 12 days in a study by DEY et al. ${ }^{4}$

In 3 pts CXR showed extension of consolidation into contiguous lobe within $48 \mathrm{hrs}$. 95\% of our patients showed lobar pattern of involvement and 5\% showed interstitial pattern where results were similar to the study by S.Bansal et al. ${ }^{2}$ the pattern of lobar involvement was seen in $80 \%$ of and $20 \%$ had interstitial pattern and right lower zone was most commonly involved which was same as our study, then followed by left lower zone. and percentage of pleural effusion was similar that of our study, multilobar involvement was seen in $15.7 \%$ of patients which is not matching with our study.

In study by Aydogduet al. ${ }^{3}$ multi lobar involvement was almost similar to that of our study. In study by DEY et al. 4 $42.86 \%$ of patients had lobar pattern and $19.45 \%$ had bilateral involvement.

Sputum Staining: In our study 86 pts showed Gram Positive Cocci and 41 pts had Gram Negative Bacilli.2\% patients needed BAL as they were not yielding good amount of sputum showed similar results with the study by the S.Bansal et al. ${ }^{2}$ where $8.57 \%$ needed BAL .

Complete Hemogram: Most common finding in our study wasNeutrophilicleucocytosis (65 patients), 12 pts had thrombocytosis and 20 pts had thrombocytopenia. In the study by S.Bansalet al ${ }^{2}$ only $11.45 \%$ had leucocytosis.

Complications Related to Cap: In our study 16 pts needed invasive ventillatory support and 2 pts required Noninvasive ventilation. 15 pts needed inotropic support 7 pts had to undergo dialysis secondary to sepsis (5 pts had Acute on CKD and 2 were $\mathrm{k} / \mathrm{c} / \mathrm{o}$ cases of ESRD). Out of 16 patients who died,13 had Sepsis and MODS and 3 died due to ARDS. 
2 pts required prolonged ventilator support and both needed Tracheostomy for purpose of prolonged ventilatory support but one 1 gave consent for the same and another did not underwent the procedure.

In study by S.Bansa et al. ${ }^{2} 10$ patients had one or more complications out of that 3 each had empyema and 3 had septic shock respectively 2 patients had pulmonary embolism and 2 had septic arthritis which was not noticed in our study.

In the study by DEY et al. ${ }^{4} \mathrm{t} 18.05 \%$ of patients had respiratory failure and $22.23 \%$ had septicemia and MODS.

PATHOGENS ISOLAED: In our study we were able to find the etiological agent in $43 \%$ of patients. Among the isolated pathogens pneumocooci was found to be the most common organism isolated.

In the study by S.Bansal et al.2 they had same results where sputum culture was positive in $71.2 \%$ and pneumococci was the most common isolated organism $35.8 \%$.

In the study by Aydogduet al3most common pathogen was Methicillin sensitive Staph and 2nd most common was pneumococci and rest of organisms were similar to our study results.

ANTIBIOTIC SENSTIVITY PATTERN: Out of 3 isolated pneumococci I organism was resistant to all drugs and sensitive only to imipenem. Most of staph were resistant to penicillins including Pip + Taz. Out of 9 only 1 was sensitive to Extended Spectrum Penicillin and 2 was sensitive to Erythromycin and Azithromycin.

Out of 5 klebsiella isolated 3 reports were resistant to Penicillins and 3rd generation Cephalosporins and 2 organisms were sensitive to Azithromycin.50\% of Acinetobacter were sensitive to Cephalosporinsand 50\% were resistant to them.

OUT COME OF PATIENTS: $84 \%$ of patients included in our study improved and $16 \%$ of patients did not survive. Among the patients who didn't survive 7 patients were aged 65 and above.In the study by S.Bansalet al mortality was $11 \%$ and they were particularly elderly people.

\section{COMPARISON OF VARIOUS CLINICAL VARIABLES IN THE} SURVIVED AND NON SURVIVED PATIENTS: Comparison of various clinical variables yielded almost similar results when compared with studies like DEY et al. ${ }^{4}, A y d o g d u$ et $\mathrm{al}^{3}$ and B.A.Shah et $a{ }^{5} \mathrm{And}$ also presence of altered mental status, breathlessness, low serum albumin levels and acidosis in ABG were bad prognostic indicators and these results were statistically significant. The severity of the breathlessness was directly proportional to death as an outcome and this observation was statistically significant ( $p$ value $<0.0001$ ).

PATHOGENS IN RELATION WITH MORTALITY: 10 out of 16 patients who died the pathogen could not be isolated, in 2 cases mixed pathogens were isolated and in other 2 klebsiella was isolated .in 1 patient pseudomonas, and other acinetobacter was isolated.

ANALYSIS OF SCORING SYSTEMS: In our study the mortality gradually increased as the PSI severity increases but the difference which we noticed is our study had no mortality even in PSI 1 and 2 class which is similar to B. A. Shah et al. ${ }^{5}$

In comparison of Sensitivity, specificity, negative and positive predictive values for different PSI classes for predicting death as an outcome we had same results when compared with results of B.A.Shah et al. ${ }^{5}$ we had high specificity (60.71) and high sensitivity (93.75) but if we take class 4 above as one group and class 4 and below as another group as cut off result was statistically significant $(\mathrm{p}=0.000)$.

In comparison of Sensitivity, specificity, negative and positive predictive values for different CURB 65 classes for predicting death as an outcome we had equal results when compared with results of B.A.Shah et al5 , if we take class 3 and above as one group, class 3 and below another group sensitivity and specificity was statistically significant $(p=0.000)$.we found more mortality in class 4 because of more severe morbidities, antibiotic resistence and complications

In comparison of sensitivity, specificity, negative and positive predictive values for different PSI classes in predicting ICU admission as an outcome also showed same results when compared with results of B.A.Shah et al5 we got high sensitivity (83.33), specificity (63.13).if we take class 4 and above as one group and class 4 below as other group it was statistical significant $(\mathrm{p}=0.000)$

In comparison of Sensitivity, specificity, negative and positive predictive values for different CURB 65 classes for classes in predicting ICU admission as an outcome we had equal results when compared with results of B.A.Shah if we take class 4 and above as one group and class 4 and below as another group sensitivity increased and it was statistically significant Mean duration of fever after admission to hospital-2.39 days (range 0-9days)-indicates average defervesce time.

The need of hospital admission increases in class 4 because of severity of illness, need of parenteral antibiotics and interventions

CLINICAL SIGNS: 42 pts had tachycardia, 25 pts had $S B P \leq 90$ mmHg. 28 pts had DBP $\leq 60 \mathrm{mmHg}, 42$ pts had RR $\geq 30 \mathrm{mmHg}, 10$ pts had presented with Altered sensorium. (Only 4 were above 65), 17 pts had Cyanosis, (7 were above 65), 11 pts had Asterexis ( 9 of them had COPD), 5 pts were above 65.

Most common clinical sign was crepitations which was present in $94 \%$ of cases. Bronchial breathing was present in $40 \%$ of cases at admission.

Even study by S.Bansalet $\mathrm{al}^{2}$ had crepitations as most common respiratory sign, and percentage of patients with bronchial breath sounds also were similar.

DURATION OF STAY: Mean duration of stay for patients is 8.99 days (range 1 - 39 days) in our study, which is comparable with study by S.Bansalet $\mathrm{al}^{5}$ with duration of 9.11 days (range 2-21 days).

The mean duration of stay was patients treated with antibiotics prior to hospitalization $(10.98+6.776$ days $)$ was more in comparison with patients who did not receive them $(7.86+6.066$ days) prior to hospitalization this observation was statistically significant. ( $p$ value -0.262 ).

The mean duration of stay in patients with BMI $<20$ $(11.34+4.88$ days $)$ was more in comparison with patients 
with BMI of $>20(7.50+6.79$ days $)$ this observation was statistically highly significant.( $p$ value -0.0062 ).

The mean duration of stay in patients with COPD $(11.2+7.36426$ days) was more in comparison with patients without COPD $(7.62+5.7623$ days $)$ this observation was statistically highly significant. ( $p$ value -0.964 ).

The mean duration of stay in patients with AGE 65 and above (11.60+5.14 days) was more in comparison with patients of AGE below $65(7.24+3.86$ days) this observation was statistically highly significant. ( $p$ value -0.0001 ).

CHEST RADIOGRAPHY: In our study most common site of involvement was lower zone followed by mid zone and least

\section{BIBLIOGRAPHY:}

1. Guest JF, Morris A. Community-acquired pneumonia: the annual cost to the National Health Service in the United Kingdom. EurRespir J 1997; 10: 1530-4.

2. SBansal, S kashyap, L. S. Pal, A. Goel. Clinical and Bacteriological Profile of Community Acquired Pneumonia in Shimla, Himachal Pradesh. Indian J Chest Dis Allied Sci 2004;46:17-22.

3. Muge AYDOGDU, Ezgi OZYILMAZ, Handan AKSOY, Gul GURSEL, Numan EKIM. Mortality prediction in community-acquired pneumonia requiring maechnicalventilation; values of pneumonia and intensive care unit severity scores. TuberkulozveToraksDergisi 2010; 58:25-34. common site was upper zone. And $95 \%$ of patients had this lobar pattern. $6 \%$ of patients had Right upper zone, $6 \%$ Left upper zone, $23 \%$ of patients had Right mid zone, $20 \%$ of patients had Left mid zone, $57 \%$ of patients had Right lower zone which was most common of all zones and 54\% of patients had Left lower zone involvement which was $2^{\text {nd }}$ most common of all zones.

$5 \%$ of patients had interstitial pattern of involvement. 17 pts had involvement of $>1$ zone on same side. 39 pts had involvement of both lungs. $11 \mathrm{pts}$ had effusion at the time of admission. 6 pts had effusion in CXR taken at $48 \mathrm{hrs}$ of which 4 pts it Was not able to aspirate any fluid.

4. A. B. Dey, K. M. Nagarkar, Vinod Kumar. Clinical presentation and predictors of outcome in adult patients with community acquired pneumonia The National Medical Journal Of India; 10: No 4, 1997.

5. Bashir Ahamed Shah, Wasim Ahmed, Ghulam Nabi Dhobi, Naveed Nazir Shah, Syed Quibtiya Khursheed And Inaamul Haq. Validity Of Pneumonia Severity Index And Curb 65 Severity Scoring Systems In Community Acquired Pneumonia In Indian Setting; The Indian Journal Of Chest Diseases And Allied Sciences; 2010; vol.52:9-17.

\begin{tabular}{|c|c|c|c|}
\hline \multirow{2}{*}{ AGE } & MALE (\%) & FEMALE (\%) & \multirow{2}{*}{ TOTAL (\%) } \\
\cline { 2 - 3 } & $49(62.22 \%)$ & $25(33.78 \%)$ & $74(100 \%)$ \\
\hline$<65$ & $16(61.54 \%)$ & $10(38.46 \%)$ & $26(100 \%)$ \\
\hline$\geq 65$ & $\mathbf{6 5 ( 6 5 . 0 0 \% )}$ & $\mathbf{3 5}(35.00 \%)$ & $\mathbf{1 0 0}(100 \%)$ \\
\hline TOTAL (\%) & \multicolumn{3}{|c|}{ Table 1: Distribution of Age and Sex } \\
\hline \multicolumn{2}{|c|}{} \\
\hline
\end{tabular}

\begin{tabular}{|c|c|c|c|}
\hline \multirow{2}{*}{ Sex } & $<55(\%)$ & $\geq 55(\%)$ & \multirow{2}{*}{ Total } \\
\cline { 2 - 4 } & $14(21.54 \%)$ & $51(78.46 \%)$ & $65(100 \%)$ \\
\hline Male & $15(42.86 \%)$ & $20(57.14 \%)$ & $35(100 \%)$ \\
\hline Female & $29(29.00 \%)$ & $\mathbf{7 1 ( 7 1 . 0 0 \% )}$ & $\mathbf{1 0 0 ( 1 0 0 \% )}$ \\
\hline Total & \multicolumn{3}{|c|}{ TABLE 2: Cap in Relation with Age 55 and More } \\
\hline \multicolumn{3}{|c|}{}
\end{tabular}

\begin{tabular}{|c|c|c|c|c|c|c|}
\hline \multirow{2}{*}{ Admission } & \multicolumn{7}{|c|}{ ATS Grade } & \multirow{2}{*}{ Total } \\
\cline { 2 - 6 } & None(\%) & Mild(\%) & Moderate(\%) & Severe(\%) & Very Severe(\%) & \\
\hline ICU & $4(16.67)$ & $0(0.00)$ & $0(0.00)$ & $1(4.17)$ & $19(79.17)$ & $24(100)$ \\
\hline E.WARD & $4(14.81)$ & $4(14.81)$ & $9(33.33)$ & $5(18.52)$ & $5(18.52)$ & $27(100)$ \\
\hline WARD & $35(71.43)$ & $8(16.33)$ & $4(8.16)$ & $2(4.04)$ & $0(0.00 \%)$ & $49(100)$ \\
\hline TOTAL & $\mathbf{4 3 ( 4 3 . 0 0 )}$ & $\mathbf{1 2 ( 1 2 . 0 0 )}$ & $\mathbf{1 3}(13.00)$ & $\mathbf{8}(8.00)$ & $\mathbf{2 4}(24.00)$ & $\mathbf{1 0 0}(100)$ \\
\hline \multicolumn{7}{|c|}{ Table 3: Comparison of admission with ATS grading of breathlessness } \\
\hline
\end{tabular}




\begin{tabular}{|c|c|}
\hline FACTOR & NO. OF PATIENTS \\
\hline COPD & 32 \\
\hline Smokers (most common risk factor) & 47 \\
\hline DM (most common co-morbidity) & 40 \\
\hline Rhinitis (allergic/infective) & 25 \\
\hline Old pulmonary TB & 7 \\
\hline Asthmatics & 6 \\
\hline Malignancy & 4 \\
\hline Alcoholics & 18 \\
\hline Home02 therapy & 2 \\
\hline Hypertension & 24 \\
\hline Cardiac disease & 10 \\
\hline Cerebrovascular Accident & 5 \\
\hline CKD & 1 \\
\hline \multicolumn{2}{|c|}{ Tables 4: Depict many risk factors and co-morbidities of CAP most } \\
common co-morbidity is DM and most common risk factor being Smoking \\
\hline
\end{tabular}

And 28 of 100 patients had $>1$ co-morbid condition mentioned above26 patients were already initiated on antibiotics prior to admission elsewhere.

\begin{tabular}{|c|c|c|c|}
\hline PRIOR TREATMENT & Patients & Mean Duration & Std. Deviation \\
\hline NO & 71 & 7.86 & 6.06603 \\
YES & 29 & 10.98 & 6.77654 \\
\hline \multicolumn{3}{|c|}{ Table 5: Prior Antibiotic treatment and Duration of stay } \\
\hline
\end{tabular}

Table 5 compares the mean duration of stay in patients treated with antibiotics prior to admission. The calculated value of independent t-test is 2.2576 for 98 degrees of freedom at $5 \%$ level of significance and p-value is $0.0262(<0.05)$ significant. The patients who treated with antibiotics prior to the admission the mean duration of stay was more.

\begin{tabular}{|c|c|c|}
\hline PATHOGEN & SENSITIVE & RESISTANT \\
\hline KLEBSIELLA & $\begin{array}{c}\text { Pip+taz, imipenem, tigecycline, } \\
\text { gentamycin, amikacin, } \\
\text { meropenem }\end{array}$ & $\begin{array}{l}3^{\text {rd }} \text { Generation } \\
\text { Cephalosporin's, } \\
\text { gentamycin, } \\
\text { cotrimoxazole, } \\
\text { ciprofloxacin }\end{array}$ \\
\hline PNEUMOCOCCI & $\begin{array}{c}\text { Pencilliin, amoxilcillin, pip+taz, } \\
\text { imipenem }\end{array}$ & \\
\hline STAPH & $\begin{array}{c}\text { Cefriaxone, cefotaxime, } \\
\text { cefoperazome, clindamycin, LNZ, } \\
\text { cortrimoxazole, tetracycline, } \\
\text { imipenem }\end{array}$ & Penicillins \\
\hline MORAXELLA & Penicillinsandcephalosporins & \\
\hline ACINETOBACTER & Ceftriaxone, ciprofloxacin, & Pip+taz \\
\hline PSEUDOMONAS & $\begin{array}{l}\text { Ceftazidime, imipenem, } \\
\text { meropenem, ertapenem }\end{array}$ & $\begin{array}{l}\text { Penicillns, pip+taz, } \\
\text { 3rd Generation, } \\
\text { cephalosporin, } \\
\text { amikacin }\end{array}$ \\
\hline
\end{tabular}

Out of 3 isolated pneumococcal 1 organism was resistant to all drugs and sensitive to only imipenem. Most of staph are resistant to penicillin's including piperacillin+tazobactam. Out of 4 only one 1 was sensitive to extended spectrum penicillin and 2 were sensitive to erythromycin and azitromycin. Among 5 klebsiella, 3 were resistant to penicillin's and 3 rd generation cephalosporin's and 2 organisms was sensitive to azithromycin. 58\% of acinetobacter were sensitive to cephalosporin'sand 50\% were resistant to them.

\begin{tabular}{|c|c|c|c|}
\hline FACTOR & SURVIVED (84) & DIED (16) & P VALUE \\
\hline PR & $101.5 \pm 18.05$ & $104.55 \pm 19.7$ & 0.5429 \\
\hline DBP & $72.98 \pm 13.76$ & $68.23 \pm 20.84$ & 0.2504 \\
\hline SPO2 & $93.36 \pm 6.94$ & $82.73 \pm 14.99$ & 0.0001 \\
\hline RR & $24.99 \pm 4.79$ & $32.81 \pm 9.18$ & 0.0001 \\
\hline BMI & $21.19 \pm 2.87$ & $23.12 \pm 1.24$ & 0.0098 \\
\hline TLC & $11560.80 \pm 525.9$ & $14722.23 \pm 629.143$ & 0.0187 \\
\hline NA LEVELS & $134.58 \pm 4.99$ & $133.22 \pm 3.16$ & 0.2970 \\
\hline UREA & $50.19 \pm 34.08$ & $80.56 \pm 56.92$ & 0.0047 \\
\hline BUN & $24.66 \pm 15.93$ & $38.71 \pm 23.59$ & 0.0037 \\
\hline ALBUMIN & $2.82 \pm 0.56$ & $3.12 \pm 0.45$ & 0.0462 \\
\hline SBP & $116.09 \pm 21.22$ & $100.67 \pm 24.89$ & 0.0104 \\
\hline Tabi
\end{tabular}

Table 7: Comparison of Various Clinical Variables in Survived and Died Patients 
Table 7 show the difference of some poor prognostic factors in CAP but only results with saturation SPO2, RR, BMI, TLC, Urea, BUN and serum albumin were statistically significant.

\begin{tabular}{|c|c|c|c|}
\hline Variables & Yes (\%) & No (\%) & Total (\%) \\
\hline Survived & 78 & 6 & $84(100)$ \\
\hline Died & 12 & 4 & $16(100)$ \\
\hline Total & $\mathbf{9 0}$ & $\mathbf{1 0}$ & $\mathbf{1 0 0}(100)$ \\
\hline \multicolumn{2}{|c|}{ Table 8: Comparison of Prognosis with Altered Mental Status } \\
\hline
\end{tabular}

\begin{tabular}{|c|c|c|c|c|c|c|}
\hline ABG & TIRF & T2RF & Acidosis & Alkalosis & Normal & Total \\
\hline Survived & $18(21.43)$ & $6(7.14)$ & $7(8.33)$ & $1(1.19)$ & $52(61.90)$ & $84(100)$ \\
\hline Died & $3(18.75)$ & $1(6.25)$ & $10(62.50)$ & $1(6.25)$ & $1(6.25)$ & $16(100)$ \\
\hline Total & $\mathbf{2 1 ( 2 1 . 0 0 )}$ & $\mathbf{7 ( 7 . 0 0 )}$ & $\mathbf{1 7 ( 1 7 . 0 0 )}$ & $\mathbf{2 ( 2 . 0 0 )}$ & $\mathbf{5 3 ( 5 3 . 0 0 )}$ & $\mathbf{1 0 0 ( 1 0 0 )}$ \\
\hline \multicolumn{7}{|c|}{ Table 9: Impact of Blood Gas Analysis on Prognosis } \\
\hline
\end{tabular}

\begin{tabular}{|c|c|c|c|}
\hline PATHOGENS & SURVIED & DIED & TOTAL \\
\hline NO GROWTH & 47 & 10 & 57 \\
\hline KLEBSIELLA & 3 & 2 & 5 \\
\hline ACINETOBACTER & 3 & 1 & 4 \\
\hline STAPHYLOCOCCUS & 9 & 0 & 9 \\
\hline MORAXELLA & 4 & 0 & 4 \\
\hline PNEUMOCOCCI & 15 & 0 & 15 \\
\hline PSEUDOMO NAS & 3 & 1 & 4 \\
\hline MXED & 0 & 2 & $\mathbf{1 0 0}$ \\
\hline TOTAL Table 10: Pathogens in Relation with Mortality \\
\hline \multicolumn{4}{r}{} \\
\hline
\end{tabular}

Table 10 depicts about the pathogens causing mortality in CAP, in this table we can appreciate that in 10 out of 16 patients who died the pathogen could not be isolated, in 2 cases mixed pathogens were isolated and in other 2 klebsiella was isolated in 1 patient pseudomonas, and other acinetobacter was isolated.

\section{ANALYSIS OF SCORING SYSTEMS:}

\begin{tabular}{|c|c|c|c|c|c|c|}
\hline Variable & Class 1 & Class 2 & Class 3 & Class 4 & Class 5 & Total \\
\hline Survived & $18(21.43)$ & $15(17.86)$ & $18(21.43)$ & $24(28.57)$ & $9(10.71)$ & $84(100)$ \\
\hline Died & $0(0.00)$ & $1(6.25)$ & $0(0.00)$ & $4(25.00)$ & $11(68.75)$ & $16(100)$ \\
\hline Total & $\mathbf{1 8}(18.00)$ & $\mathbf{1 6}(16.00)$ & $\mathbf{1 8}(18.00)$ & $\mathbf{2 8}(28.00)$ & $\mathbf{2 0}(20.00)$ & $\mathbf{1 0 0}(100)$ \\
\hline \multicolumn{7}{c}{ Table 11: Mortality In Different Psi Classes } \\
\hline
\end{tabular}

\begin{tabular}{|c|c|c|c|}
\hline PSI CLASS & \multicolumn{3}{|c|}{ MORTALITY PREDICTION } \\
\hline & DIED & SURVIVED & TOTAL \\
\hline$\geq 4$ & 15 & 33 & 48 \\
\hline$<4$ & 1 & 51 & 52 \\
\hline TOTAL & 16 & 84 & 100 \\
\hline Table 12: Psi Scoring in Predicting Death (If Class 4 and above are Taken as Cut Off) \\
\hline
\end{tabular}

SENSITIVITY - 93.75\% SPECIFICITY-60.71\% PPV-31.25\% NPV-98.08 (p VALUE -0.000)

\begin{tabular}{|c|c|c|c|c|c|}
\hline Variable & Low risk & Mod risk & Severe risk & Highest risk & Total \\
\hline Survived & $47(55.95)$ & $27(32.14)$ & $9(10.71)$ & $1(1.19)$ & $84(100)$ \\
\hline Died & $0(0.00)$ & $7(43.75)$ & $3(18.75)$ & $6(37.50)$ & $16(100)$ \\
\hline Total & $\mathbf{4 7 ( 4 7 . 0 0 )}$ & $\mathbf{3 4 ( 3 4 . 0 0 )}$ & $\mathbf{1 2 ( 1 2 . 0 0 )}$ & $\mathbf{7 ( 7 . 0 0 )}$ & $\mathbf{1 0 0}(\mathbf{1 0 0})$ \\
\hline \multicolumn{7}{|c|}{ Table 13: Mortality in Different Curb-Risk Class } \\
\hline
\end{tabular}

